Understanding and eliminating minority health disparities in a 21st-century pandemic: A White Paper Collection
Differential Impacts of COVID-19 in New York State: Understanding and eliminating minority health disparities in a 21 st-century pandemic

2021

\title{
COVID-19 Mortality in New York City across Neighborhoods by Race, Ethnicity, and Nativity Status
}

Samantha Friedman University at Albany, State University of New York, samfriedman@albany.edu

Tabassum Insaf University at Albany, State University of New York, tabassum.insaf@health.ny.gov

Jin-Wook Lee University at Albany, State University of New York, jwlee@albany.edu

Temilayo Adeyeye University at Albany, State University of New York, Temilayo.Adeyeye@health.ny.gov

Please contact the following author for an updated version of this work prior to citing it:

Samantha Friedman

University at Albany, State University of New York

samfriedman@albany.edu

Part of the Public Health Commons

\section{Recommended Citation}

Friedman, Samantha; Insaf, Tabassum; Lee, Jin-Wook; and Adeyeye, Temilayo. 2021. "COVID-19 Mortality in New York City across Neighborhoods by Race, Ethnicity, and Nativity Status" Understanding and eliminating minority health disparities in a 21st-century pandemic: A White Paper Collection. University at Albany, SUNY: Scholars Archive.

https://scholarsarchive.library.albany.edu/covid_mhd_nys_white_papers/8

In April 2020, the University at Albany was asked by Gov. Andrew Cuomo to research why communities of color in New York have been disproportionately impacted by COVID-19. The goal of this research, carried out in partnership with the New York State Department of Health and Northwell Health, is to add to the existing well of knowledge about health disparities in New York State by identifying the environmental, socioeconomic and occupational factors that explain why COVID-19 has disproportionately harmed Black and Hispanic New Yorkers and to propose practical intervention strategies to eliminate these disparities and save lives.

For additional information about this project please see: www.albany.edu/mhd or contact Theresa Pardo, Special Assistant to the President and Project Director for this initiative at tpardo@ctg.albany.edu. 


\title{
COVID-19 Mortality in New York City across Neighborhoods by Race, Ethnicity, and Nativity Status
}

\author{
Samantha Friedman* \\ Associate Professor of Sociology \\ University at Albany, SUNY \\ samfriedman@albany.edu \\ Tabassum Insaf \\ Research Director \\ Bureau of Environmental and Occupational Epidemiology \\ New York State Department of Health \\ Assistant Professor of Epidemiology and Biostatistics \\ University at Albany, SUNY \\ tabassum.insaf@health.ny.gov \\ Jin-Wook Lee \\ GIS Specialist \\ Center for Social and Demographic Analysis \\ University at Albany, SUNY \\ jwlee@albany.edu \\ Temilayo Adeyeye \\ Research Scientist \\ Bureau of Environmental and Occupational Epidemiology \\ New York State Department of Health \\ Research Assistant Professor of Department of Environmental Health Sciences \\ University at Albany, SUNY \\ Temilayo.Adeyeye@ health.ny.gov
}

April 26, 2021

*Direct correspondence to Samantha Friedman, Department of Sociology, University at Albany, SUNY, 348 Arts and Sciences Building, 1400 Washington Avenue, Albany, NY 12222 (samfriedman@albany.edu); phone (617-447-9407). Support for this research was provided by the Center for Social and Demographic Analysis at the University at Albany. 


\title{
COVID-19 Mortality in New York City across Neighborhoods by Race, Ethnicity, and Nativity Status
}

\begin{abstract}
New York City has lost more lives from COVID-19 than any other American city. Our paper examines variation in COVID-19 deaths across neighborhoods as it relates to the spatial variation in the racial, ethnic, and nativity-status composition of neighborhoods. This topic has received little scholarly attention and is imperative to explore, given the absence of racial and ethnic specific COVID-19 mortality rates by neighborhood. New York City is a racially and ethnically segregated city and a longstanding destination of immigrants, making some neighborhoods more susceptible to greater levels of COVID-19 mortality than others. Using ZCTA-level data on COVID-19 deaths and demographic data from the American Community Survey, our mapping analysis reveals that a racial, ethnic, and nativity-status hierarchy exists in the geographic distribution of COVID-19 mortality. Implications of these findings are discussed as they relate to residential segregation and persistent spatial inequalities faced by communities of color.
\end{abstract}

Keywords: COVID-19 mortality, New York City, minority neighborhood health disparities, mapping 
New York City (NYC) has experienced a significant share of deaths from the COVID-19 pandemic within the United States (Wadhera et al. 2020). At the time of this writing, four of the five counties - Bronx, Kings, Queens, and New York - that make-up NYC have numbers of deaths in the top 20 counties in the United States, out of the more than 3000 counties (USA Facts 2020). Out of all the deaths from COVID-19 in the United States, one in 17.6 was in NYC (USA Facts 2020).

Research has consistently shown that COVID-19 mortality rates across the U.S. vary by race and ethnicity (U.S. Centers for Disease Control and Prevention 2020; Yancy 2020). The percentage of Blacks and Hispanics dying from COVID-19 exceeds their shares of the population, respectively, and both groups have higher mortality rates from COVID-19 than Whites (U.S. Centers for Disease Control and Prevention; Yancy 2020). Blacks and Hispanics in NYC have also experienced higher rates of age-adjusted, mortality than their white and Asian counterparts (Hooper et al. 2020).

Racial- and ethnic-specific mortality rates, however, are unavailable at the neighborhood level in NYC, making it difficult to pinpoint communities of color and also, immigrant communities that may be hardest hit by the pandemic. Recent research has found that non-White communities in NYC have higher numbers of positive, COVID-19 tests than majority-White communities (e.g., DiMaggio et al. 2020; Lieberman-Cribbin et al. 2020). However, little research has explored the geographic variation in COVID-19 mortality rates across neighborhoods in NYC alongside with spatial variation in the racial, ethnic, and nativitystatus composition of these communities. ${ }^{1}$

\footnotetext{
${ }^{1}$ At the county-level of analysis, however, there have been several studies examining racial and ethnic disparities in mortality (e.g., Millett et al. 2020; Strully et al. 2020).
} 
This study seeks to fill the gap that exists at the neighborhood level of analysis and explores the geographic variation in COVID-19 mortality rates across neighborhoods in NYC, defined by Zip Code Tabulation Areas (ZCTA), as patterned by the racial, ethnic, and nativity status compositions of the population in those neighborhoods. To achieve this goal, we create bivariate maps to describe the patterns of COVID-19 mortality across communities (ZCTAs) of color and immigrants in NYC. This study's use of the bivariate mapping methodology provides a systematic way for researchers to simultaneously examine the geographic variation in COVID19 mortality rates and the racial, ethnic, and nativity-status compositions of neighborhoods in NYC, and identify neighborhoods of people of color and immigrants that have endured the most loss from the pandemic. This method is one way to overcome the challenges faced by researchers and policymakers that have arisen due to the lack of data on mortality from COVID-19 disaggregated by race and ethnicity at geographic levels lower than the county level.

\section{Background}

New York City as a Residentially Segregated Context and Immigrant Destination

In order to understand how COVID-19 mortality rates vary across NYC's neighborhoods and relate to the geographic variation in the racial, ethnic, and nativity-status composition of these neighborhoods, it is first necessary to focus on two important characteristics that sets NYC apart from many other cities in the U.S. First, NYC has had unusually high levels of racial and ethnic residential segregation (Hotchkiss 2015; Massey and Tannen 2015). Second, NYC has historically been a premier destination for immigrants from many countries throughout the world, and unlike other U.S. immigrant destinations, NYC has witnessed significant diversity in the in-flows of people from around the globe (Lobo and Salvo 2013; Foner 2000; Rosenbaum 
and Friedman 2007). As we discuss below, these unique features of NYC impact the population demographics within its neighborhoods and make some neighborhoods more vulnerable to deaths from the COVID-19 pandemic than others.

Although NYC has long been a city where non-Whites are the numerical majority of the population, its multi-racial and ethnic character has not translated into complete racial and ethnic residential integration (Lobo et al. 2019). To the contrary, with respect to Black-White residential segregation, NYC has been demarcated as a "hyper-segregated" city continuously for five decades since 1970 (Hotchkiss 2015; Massey and Tannen 2015). In 2010, the index of dissimilarity or D-score (a measure of community segregation) was 81.4 indicating that, $81.4 \%$ of either Blacks or Whites would have to move to achieve an even distribution within the city (Logan and Stults 2011). This level of segregation falls in what is considered to be the "high range," and in 2010, this score was the second highest score among the 200 largest cities in the U.S. (Logan and Stults 2011; Massey and Denton 1993).

New York City's levels of residential segregation are also unusually high for Hispanics and Asians, relative to Whites. The D-score gauging Hispanic-White residential segregation was in the high range at 65.8 (Logan and Stults 2011). Similar to the Black-White residential segregation level in NYC, in 2010 the Hispanic-White D-score was the second highest level of Hispanic-White segregation out of the 200 largest cities in the U.S. (Logan and Stults 2011). The Asian-White level of segregation in NYC - 50.6 -- was lower than the Black-White and Hispanic-White D-scores, but it was the seventh largest value out of 200 of the largest cities in 2010 (Logan and Stults 2011).

Against this backdrop of residential segregation, NYC continues to be a primary destination for many immigrants coming to the U.S. According to data from the 2019 American 
Community Survey (ACS), NYC had the largest foreign-born population - 3.1 million -- of any city in the U.S., which was 7\% of all the foreign-born population in the nation (U.S. Census Bureau 2020a). What is unique about NYC's immigrant population is that no one group of immigrants dominates the flow of foreign-born persons to the city (Lobo and Salvo 2013). In 2011, Dominicans, Chinese, Mexicans, Jamaicans, and Guyanese were the top five groups immigrating to NYC, with each group representing $12.4 \%, 11.4 \%, 6.1 \%, 5.5 \%$, and $4.6 \%$, respectively, of the flow to NYC during that year (Lobo and Salvo 2013: 13).

The large number of immigrants to NYC and the diversity in their origins has resulted a larger share of each racial and ethnic group in NYC to have foreign-born origins than in the U.S. as a whole. According to 2019 ACS data, in NYC, the share of whites, blacks, Hispanics, and Asians that were born outside of the U.S. were $22 \%, 32 \%, 40 \%$, and $71 \%$, respectively; in the U.S. the share of whites, blacks, Hispanics, and Asians that were born outside of the U.S. were $4 \%, 10 \%, 33 \%$, and 66\%, respectively (U.S. Census Bureau 2020b). The fact that such large shares of each racial and ethnic group are immigrants not only has an impact on how they settle in NYC, especially relative to the segregation that exists in the city, but such residential location will also have implications for how COVID-19 affects communities of color and immigrants. Theoretical Models of Residential Segregation as a Background to the Impact of the Pandemic

In order to characterize how such neighborhoods will be impacted by the pandemic, we must first understand why contemporary levels of residential segregation in NYC are so high. Two theoretical models have generally been used in the literature to explain why racial and ethnic segregation exists within cities - the spatial assimilation model and the place stratification model (Charles 2003; Massey 1985; Massey and Denton 1993). The spatial assimilation model maintains that the primary factors that explain the residential segregation of non-Whites from 
Whites are differences in socioeconomic status, nativity status, time in the U.S., and English language proficiency. The tenets of the model suggest that once non-White groups have achieved upward socioeconomic mobility, resided in the U.S. for a number of years, and become proficient in English, they will seek to bring their residential attainment in line with their improved social status and segregation between non-Whites and Whites will decline (Alba and Logan 1991; Charles 2003; Massey 1985). The principles of the spatial assimilation model have received empirical support and suggest that the residential segregation observed in NYC for many groups is temporary as they achieve upward socioeconomic mobility and for foreign-born individuals, as they integrate into U.S. culture (Iceland and Nelson 2008; Iceland and Scopilliti 2008; Iceland and Wilkes 2006; Logan et al. 2002).

Historically, neighborhoods in NYC like Chinatown are symbolic of the types of neighborhoods discussed by the spatial assimilation model, where immigrants initially settle before they experience residential integration, usually moving to NYC's suburbs (Rosenbaum and Friedman 2007). Since 1980, because the flow of immigrants from China to NYC has been large, Chinatown has been unable to house all of the immigrants, and there has been an emergence of other immigrant enclaves, similar to Chinatown, in the neighborhoods of Flushing in Queens and Sunset Park in Brooklyn and in neighborhoods near those satellite Chinatowns, like Elmhurst, Jackson Heights, and Corona in Queens and Bay Ridge, Borough Park, and Gravesend in Brooklyn (Rosenbaum and Friedman 2007). The settlement of the Soviet Jewish refugees and more recently, Asian Indians, has taken on a similar nature to the Chinese and also fits with the tenets of the spatial assimilation model (Logan et al. 2002; Rosenbaum and Friedman 2007). 
The persistence of Black-White segregation, however, cannot be fully explained by the spatial assimilation model. Studies have found that affluent Blacks reside in neighborhoods with fewer Whites than similarly situated Hispanics and Asians, suggesting that other forces, besides economics, shape Blacks' residential separation from Whites (Iceland and Wilkes 2006; Intrator et al. 2016). The place stratification model has been used to explain Black exceptionalism in their residential segregation from Whites (Logan and Molotch 1987; Massey and Denton 1993). The tenets of this model maintain that powerful groups in society use their authority and influence on institutions in the housing market (i.e., real estate and related financial industries), most often in the form of discriminatory actions, to actively constrain the housing choices of less powerful groups so that powerful and less powerful groups remain spatially and socially distanced (Logan and Molotch 1987; Massey and Denton 1993; Turner et al. 2013). Research has consistently shown that Black segregation is much better explained by these structural factors than demographic and economic factors associated with the spatial assimilation model (Charles 2003; Iceland and Wilkes 2006; Kucheva and Sander 2018).

Historical evidence clearly shows that contemporary Black-White hyper-segregation in NYC is the outgrowth of discriminatory housing policies that operated in the early part of the $20^{\text {th }}$ century, consistent with the tenets of the place stratification model (Jackson 1985; Rosenbaum and Friedman 2007; Wilder 2000). The most influential programs on Black-White segregation were the Home Owner's Loan Corporation (HOLC), the Loan Guarantee Program of the Federal Housing Administration (FHA), and the Home Loan Guarantee Program of the Veterans Administration (VA) (Rosenbaum and Friedman 2007). The HOLC program initiated the discriminatory practice of redlining, and Wilder (2000) argues that housing developers actively colluded with the HOLC to invest in neighborhoods in southern and eastern portions of 
Brooklyn and not invest in the northern and central areas, which were largely Black. The FHA and VA programs solidified the disinvestment in northern and central Brooklyn as well as in the Bronx by facilitating White suburbanization and leaving Blacks behind in disinvested areas that become ghettos (Jackson 1985; Rosenbaum and Friedman 2007; Wilder 2000). The abandonment of these areas in Brooklyn and the Bronx had reached such epic proportions by the 1970s that housing losses in these areas alone "accounted for more than 80 percent of the net housing losses nationwide during 1970-1980”' (Rosenbaum and Friedman 2007: 123). NYC's ten-year plan, which was in operation in the late 1980s and early 1990s, restored some housing in these areas, but the legacy of this earlier racial discrimination remains (Rosenbaum and Friedman 2007).

Not all groups, however, have residential patterns that conform precisely to either the spatial assimilation or place stratification models. Dominicans and foreign-born blacks from the Caribbean and Africa are two such examples worth discussing because of the implications their residential patterns have for our expectations about variation in neighborhood-level, COVID-19 mortality rates. Since the 1970s, Dominicans have been the largest immigrant group to NYC; in 2011, about 40\% of all Latin American immigrants were Dominicans (Lobo and Salvo 2013). They have generally settled in poorer-quality housing and neighborhoods in northern Manhattan, the Bronx, and central Brooklyn, and their lower levels of residential attainment cannot be fully attributable to their lower economic status and immigrant characteristics, thereby suggesting that they face constraints in the housing market that reflect the operation of structural discrimination, which is more consistent with the place stratification model (Rosenbaum and Friedman 2007). With respect to foreign-born Blacks, although they are segregated from Whites, their higher levels of homeownership, relative to native-born Blacks, likely buffers them from the negative 
impacts of residential segregation that are probably felt more strongly by native-born Blacks; there is some evidence that suggests that Afro-Caribbean blacks maintain their voluntary segregation to maintain their ethnic communities (Crowder and Tedrow 2001; Kasinitz 1992;

Logan et al. 2002; Rosenbaum and Friedman 2007).

Residential Segregation and COVID-19 Mortality across NYC Neighborhoods

How does residential segregation impact the health of communities of color and immigrants? A large body of research links racial residential segregation and racism, more generally, to adverse health outcomes and mortality (for a review see Phelan and Link 2015). Independent of socioeconomic status, racial residential segregation that is based upon structural forces produces inequalities in neighborhoods, which have been deemed as a "fundamental cause" of racial health disparities (Williams and Collins 2001). Through several mechanisms, including the lack of recreational resources and adequate supermarkets; exposure to environmental toxins and higher levels of violent crime; and the existence of poorer quality medical care, Blacks are at a significantly greater risk of experiencing adverse, chronic health conditions and mortality than their White counterparts (Phelan and Link 2015). Recent research has used historical redlining maps from the HOLC and found statistically significant associations between redlining and the current prevalence of cancer, asthma, and lack of health insurance as well as the risk of pre-term births (Krieger et al. 2020; Nardone et al. 2020).

Given these linkages between structural racism, residential segregation, health, and mortality, we expect that COVID-19 mortality rates will be the highest in neighborhoods with larger shares of native-born Black population and the lowest in neighborhoods with larger shares of native-born White population. Neighborhoods with large shares of foreign-born Black and Hispanic population (of which Dominicans compose a sizeable share) will likely fall in between 
these two extremes because these populations have experienced constraints in their residential opportunities but not to the extent, historically, that native-born blacks have faced. However, it is unclear where neighborhoods with large percentages of Asians and foreign-born Whites will fall on this continuum because of the fact that the nature of their segregation has been largely more voluntary and economic in nature. While COVID-19 mortality has been associated with comorbidities like hypertension and diabetes that are more prevalent in neighborhoods whose populations face structural racism (Bajgain et al. 2021; Ssentongo et al. 2020), COVID-19 is highly contagious and could spread in immigrant neighborhoods that may not necessarily face such structural disadvantages but instead are built upon social networks and significant social contact (Torrats-Espinosa 2021). Thus, the high levels of more voluntary segregation exhibited by foreign-born Asians and their native-born children as part of the spatial assimilation process could result in higher levels of COVID-19 through their social interactions with co-ethnics in their segregated and densely populated communities.

\section{Data and Methods}

Two main data sources are used for our analysis of COVID-19 mortality rates in NYC neighborhoods. Data on COVID-19 deaths at the ZCTA level are acquired from data released daily by the New York City Department of Health, which we pulled on February 1, 2021 (NYC DOH 2021a). Data on the racial, ethnic, and nativity-status composition of ZCTAs are obtained from the 2014-2018, 5-year release of the American Community Survey (ACS) available via the IPUMS NHGIS website maintained by the University of Minnesota Population Center. Our unit of analysis in this study is at the neighborhood level that is defined by ZCTAs. This has been 
used in other studies examining the spatial variation in COVID-19 tests (e.g., DiMaggio et al. 2020; Lieberman-Cribbin et al. 2020). In total, there are 177 ZCTAs included in our analysis.

The primary outcome of interest is the COVID-19 mortality rate for each ZCTA, calculated as the total number of COVID-19 deaths in a ZCTA per 100,000 population. Our main independent variable of interest gauges the racial, ethnic, and nativity status composition of ZCTAs. We measure this composition with the following variables: the percentages of nativeand foreign-born Whites, Blacks, Hispanics, and Asians. Because of the way the ACS Summary File is tabulated, Blacks include Hispanics and non-Hispanics. Therefore, our Black and Hispanic compositional variables are not mutually exclusive. However, in NYC, Blacks and Hispanics are, for the most part, distinct groups. In 2019, only $12 \%$ of Blacks identified that they were of Hispanic origin, and among Hispanics, only $10 \%$ identified as being Black (U.S. Census Bureau 2020c). To examine the relation between racial, ethnic, and nativity-status composition and COVID-19 mortality, we present eight descriptive, bivariate maps of the spatial variation of COVID-19 deaths per 100,000 population across ZCTAs in NYC by their racial, ethnic, and nativity status composition.

\section{Results}

White Maps. Figure 1 presents the COVID-19 mortality rates by the percentage native-born White across ZCTAs in NYC. Areas on the map that are dark purple indicate ZCTAs that have both the highest percentages of native-born Whites and levels of COVID-19 deaths per 100,000 population (see the upper-right hand corner of the legend). Just eight out of the 177 ZCTAs in NYC fall into that category - a neighborhood in Kingsbridge-Riverdale, Bronx; a neighborhood in Flatbush in Brooklyn; ZCTAs in Flushing-Clearview, Ridgewood-Forest Hills, Southwest 
Queens, and Rockaway in Queens; and in Willowbrook and South Beach-Tottenville of Staten Island. ${ }^{2}$ There are ten ZCTAs falling into the middle category of COVID-19 mortality - the second darkest shade of purple - and the highest share of native-born, White population. Most of the neighborhoods with large shares of native-born, White population fall in the purple category at the lower right-hand corner of the legend. These ZCTAS, which number at least 25, are areas with the lowest levels of COVID-19 mortality. For example, most of the middle and southern sections of Manhattan fall in this category as well as the southern portion of Staten Island; neighborhoods in Greenpoint and Downtown-Heights-Park Slope, Brooklyn; and neighborhoods in Long-Island City-Astoria and Bayside-Little Neck, Queens. Notably, most of the ZCTAs in the Bronx, Brooklyn, and Queens fall in the two blue categories at the upper- and middleleftmost corner of the legend. These neighborhoods have the lowest shares of native-born, White population and COVID-19 mortality rates that are either in the highest or second highest categories. Thus, it is clear from the map that native-born White communities are experiencing the lowest levels of deaths from COVID-19 in NYC.

Figure 2 presents the COVID-19 mortality rates by the percentage foreign-born Whites across ZCTAs in NYC. Similar to Figure 1, there are relatively few neighborhoods (11 in total) that are shaded dark purple and contain the largest share of foreign-born White population and highest levels of COVID-19 mortality. One main difference from Figure 2 is the location of ZCTAs that have the greatest shares of foreign-born, White population and fall in the middle category in terms of COVID-19 mortality rates, the middle purple category. Neighborhoods in southern and western Brooklyn fall in this category, like Bensonhurst-Bay Ridge, Coney IslandSheepshead Bay, and Borough Park. These areas have large shares of immigrants from Eastern

\footnotetext{
${ }^{2}$ Appendix Table 1 shows the names of all of the ZCTAs, which we obtained from the NYC Department of Health website (NYC DOH 2021b).
} 
Europe, Italy, and the former Soviet Union, all of whom are older, which makes them more vulnerable to death from COVID-19 (Lobo and Salvo 2013). Indeed, these neighborhoods have greater shares of population 65 years and older than the average for NYC overall (NYU Furman 2018).

Also, in contrast to Figure 1, Figure 2 shows that there are more neighborhoods with large shares of foreign-born White population and either the highest or moderate levels of COVID-19 mortality in the middle portion of Queens -- in ZCTAs located in West and Southwest Queens and Ridgewood-Forest Hills. These neighborhoods have large percentages of immigrants from Poland, Russia, Ukraine, and other Eastern European countries (Lobo and Salvo 2013). The share of the population in Forest Hills that is 65 years and older is greater than that found in NYC as a whole (NYU Furman 2018).

As was the case in the map in Figure 1, in Figure 2, there are a number of neighborhoods with large shares of foreign-born, White population that fall into the purple category at the lower right-hand corner of the legend -- areas with the lowest levels of COVID-19 mortality. Many of these ZCTAs, which number at least 25, are located in similar places as those in Figure 1: in the middle and southern sections of Manhattan fall; parts of the southern portion of Staten Island; Greenpoint, Brooklyn; and Long Island City-Astoria, Queens. Figure 2 reveals that almost all of the ZCTAs in the Bronx; much of the central and southern parts of Brooklyn; and northern and southern Queens fall in the two blue categories at the upper- and middle-leftmost corner of the legend. These neighborhoods have the lowest shares of foreign-born, White population and COVID-19 mortality rates that are either in the highest or second highest categories.

Black Maps. The next map, Figure 3, shows the percentage of native-born Blacks by levels of COVID-19 mortality across NYC neighborhoods. It is profoundly different than the 
map for both native- and foreign-born White populations. Notably, most of the ZCTAs with large, native-born Black populations fall into either the highest or middle categories of COVID19 deaths per 100,000 population. In contrast to Figures 1 and 2, only five neighborhoods contain large Black populations and the lowest levels of COVID-19 mortality, shaded purple in the lower right-hand corner of the legend.

High levels of Black population and middle-to-high levels of COVID-19 mortality rates are found mostly in ZCTAs in the Bronx, central and eastern Brooklyn, and southeastern Queens. In the Bronx, the distribution of communities with large shares of Blacks and high rates of COVID-19 mortality is widespread and include ZCTAs in Northeast Bronx, Fordham-Bronx Park, Crotona-Tremont, High Bridge-Morrisania, Hunts Point-Mott Haven, and Pelham-Throgs Neck. In central and eastern Brooklyn, ZCTAs that contain large percentages of native-born Blacks and have among the highest levels of COVID-19 deaths per 100,000 are those in Bedford Stuyvesant-Crown Heights, Williamsburg-Bushwick, Flatbush, Canarsie-Flatlands, and East New York. Moving to southeastern Queens, the neighborhoods with the largest shares of Black population and COVID-19 mortality are ZCTAs in Jamaica, Southeast Queens, and the eastern portion of Rockaway. Many of these communities exhibit higher levels of poverty, unemployment, and crime, than found in the City as a whole (NYU Furman 2018). In Manhattan, few neighborhoods have large shares of Blacks, and those that do are in the middleto-highest ranges of COVID-19 deaths per 100,000 population in East Harlem, Central HarlemMorningside Heights, and Washington Heights-Inwood. In Staten Island, a few ZCTAs fall in the range of neighborhoods with large shares of native-born Black population and mid-to-high levels of COVID-19 mortality - in Port Richmond and Stapleton-St. George. 
Figure 4 presents a bivariate map of COVID-19 mortality rates by the percentage of the population that is foreign-born Black. By and large, the pattern of results in this figure are similar to Figure 3. The residential distribution of areas with large percentages of foreign-born Blacks across ZCTAs is very similar in nature to the distribution of areas with large percentages of native-born Blacks, and these distributions overlap with levels of COVID-19 deaths per 100,000 population that fall in the middle and highest categories. There are only a few differences. In East Harlem and Williamsburg-Bushwick, there are fewer ZCTAs with large percentages of foreign-born Blacks and middle-to-high levels of COVID-19 deaths per 100,000 population. However, in Southwest Queens and Jamaica, there are a few more ZCTAs with large shares of foreign-born Blacks and middle-to-high levels of COVID-19 mortality, which wasn't the case when examining the distribution of native-born blacks. Also similar to Figure 3, there are only six neighborhoods that have the highest level of foreign-born Black populations and the lowest level of COVID-19 mortality, shaded purple in the lower right-hand corner of the legend.

Taken together, however, Figures 1 through 4 clearly show that greater rates of mortality from COVID-19 are found in ZCTAs that have larger shares of Black population, as compared to White population, regardless of nativity status. Also significant is the fact that the location of neighborhoods with large percentages of native- and foreign-born Blacks (in Figures 3 and 4, respectively), regardless of COVID-19 mortality rates, is distinctly different from those containing larger shares of native- and foreign-born White populations (in Figures 1 and 2, respectively). These differing distributions of the residential locations of White and Black segments of the population is not surprising, however, given that NYC has experienced extraordinarily high levels of Black-White residential segregation (Hotchkiss 2015; Massey and Tannen 2015). 
Hispanic Maps. Figure 5 presents a bivariate map of COVID-19 mortality rates by the percentage of the population that is native-born Hispanic. Similar to maps for the native- and foreign-born Black populations shown in Figures 3 and 4, respectively, it is evident that most of the ZCTAs with large, native-born Hispanic populations fall into the middle or highest categories of COVID-19 deaths, which are denoted by the two shades of purple in the upper-right corner and far-right middle section of the legend. In contrast to the maps of the native- and foreign-born White populations, only nine neighborhoods contain large native-born Hispanic population and the lowest levels of COVID-19 mortality, which is shaded the color purple in the lower righthand corner of the legend.

There are similarities but also distinct differences between Figure 5 and Figures 3 and 4, in terms of the distribution of neighborhoods where native-born Hispanic population and COVID-19 mortality rates are highest. For example, there is overlap in the distributions of neighborhoods with COVID-19 deaths in the middle and high ranges and where native-born Hispanic and Black, and foreign-born Black populations are located on: the North Shore in Staten Island; and in the central, southern, and eastern sections of the Bronx in neighborhoods like Northeast Bronx, Fordham-Bronx Park, Crotona-Tremont, High Bridge-Morrisania, and Hunts Point-Mott Haven. In contrast to the maps for the native- and foreign-born Black populations, Figure 5 also reveals that more neighborhoods in Pelham-Throgs Neck and Kingsbridge-Riverdale as well as in Manhattan in Washington Heights-Inwood and Union Square-Lower East Side have large shares of native-born Hispanic population and middle-tohigh levels of COVID-19 mortality rates.

In Brooklyn and Queens, however, Figure 5 shows that the neighborhoods inhabited by large shares of native-born Hispanics and that have middle-to-high levels of COVID-19 deaths 
are different in their distribution than those with large shares of native- and foreign-born Black populations. In Brooklyn, there are very few neighborhoods that have large shares of native-born Hispanic population and middle-to-high levels of COVID-19 deaths, and they include ZCTAs in Sunset Park and Williamsburg-Bushwick, and only two neighborhoods in East New York. In Queens, the differences in the distributions of native-born Hispanic population and Black population are also evident. Whereas neighborhoods with large percentages of native- and foreign-born Black populations are located in Southeast Queens and Jamaica, ZCTAs with large shares of native-born Hispanic population are located in the northeastern and central sections of Queens in West Queens, Flushing-Clearview, and Southwest Queens. As was the case for communities with large shares of native- and foreign-born Black populations that have high levels of COVID-19 mortality rates, many of the communities with large shares of native-born Hispanic population and large numbers of deaths from COVID-19 exhibit higher levels of poverty, unemployment, and crime, than found in the City as a whole (NYU Furman 2018).

Figure 6 presents a bivariate map of COVID-19 mortality rates by the percentage of the population that is foreign-born Hispanic. For the most part, the general pattern of results here mirror those in the previous map. The residential distribution of ZCTAs with large shares of foreign-born Hispanics is very similar in nature to the distribution of ZCTAs with large shares of native-born Hispanics, and these distributions overlap with levels of COVID-19 deaths per 100,000 population that fall in the middle and highest categories. There are some exceptions, however. In the Bronx, in Northeast Bronx and Pelham-Throgs Neck; in Manhattan in the Union Square-Lower East Side; and in Staten Island along the North Shore, there are fewer ZCTAs with large percentages of foreign-born Hispanics and middle-to-high levels of COVID-19 deaths per 100,000 population as compared to ZCTAs with large percentages of native-born Hispanics 
and middle-to-high levels of COVID-19 mortality rates. On the other hand, in Queens in Long Island City-Astoria, West Queens, and Rockaway, there are more ZCTAs with large percentages of foreign-born Hispanics and middle-to-high levels of COVID-19 deaths per 100,000 population compared to those in Figure 5. Figure 6 shows there are ten neighborhoods that have the highest level of foreign-born Hispanic population and the lowest level of COVID-19 mortality, shaded purple in the lower right-hand corner of the legend. This is also similar to the pattern shown in Figure 5.

Taken together, in comparison to Figures 1 and 2, Figures 5 and 6 clearly show that greater rates of mortality from COVID-19 are found in ZCTAs that have larger shares of Hispanic population, as compared to White population, regardless of nativity status. Also notable is the fact that the location of neighborhoods with large percentages of native- and foreign-born Hispanics (in Figures 5 and 6, respectively), regardless of COVID-19 mortality rates, is distinctly different from those containing larger shares of native- and foreign-born White populations (in Figures 1 and 2, respectively). Similar to the comparison of the residential locations of Whites and Blacks, the differing distributions of the geographic locations of White and Hispanic components of the population is consistent with the fact that the NYC's level of White-Hispanic residential segregation is the second highest in the country (Logan and Stults 2011).

Asian Maps. Figures 7 and 8 present bivariate maps of COVID-19 mortality rates by the percentage of the population that is native-born Asian and foreign-born Asian, respectively. Because $71 \%$ of Asians are immigrants (U.S. Census Bureau 2021b), it is not surprising that the nature of the spatial distribution of ZCTAs with middle-to-high COVID-19 deaths per 100,000 population and large percentages of native-born Asian population is very similar in nature to the 
spatial distribution of COVID-19 mortality rates by foreign-born Asian population. Therefore, we discuss the maps together, unlike was the case for the other racial and ethnic groups in NYC.

It is evident that while many ZCTAs with large native- and foreign-born Asian populations fall into the middle or highest categories of COVID-19 deaths, which are denoted by the two shades of purple in the upper-right corner and far-right middle section of the legend, there are many ZCTAs - just under 25 -- that have low levels of COVID-19 mortality rates, which is shaded the color purple in the lower right-hand corner of the legend. Relative to the maps of the other racial/ethnic/nativity status compositional groups, it is clear that there is a more even split of neighborhoods that contain large shares of native- and foreign-born Asian population and fall into the lowest, middle, and highest levels of COVID-19 deaths per 100,000 population than is the case when examining ZCTAs that contain large shares of native- and foreign-born Black and Hispanic populations. However, it is clear that the Asian distribution, relative to mortality from COVID-19 is not as ideal as for communities predominated by Whites in NYC as revealed in Figures 1 and 2.

The distribution of neighborhoods where native- and foreign-born Asian populations and COVID-19 mortality rates are highest is distinct from the previous maps, although there are some similarities in the ZCTAs in Figures 2, 5, and 6. Starting with the similarities, there is overlap between ZCTAs with middle-to-high levels of COVID-19 mortality rates and large percentages of native- and foreign-born Asian populations and those with the same levels of COVID-19 deaths and large percentages of foreign-born White population (see Figure 2) in the following areas: in southwestern Brooklyn in Bensonhurst-Bay Ridge, Coney Island-Sheepshead Bay, and Borough Park; and in central and northeastern Queens in Ridgewood-Forest Hills and Flushing-Clearview. There is also some overlap with the distribution of ZCTAs with large shares 
of foreign-born Hispanic population and middle-to-high levels of COVID-19 deaths per 100,000 population, occurring in Queens in some ZCTAs in Southwest Queens, Jamaica, West Queens and one ZCTA in Flushing-Clearview. The distinct pattern of the intersection between middleto-high COVID-19 mortality rates and large shares of native- and foreign-born Asian populations is found in ZCTAs primarily located in northeastern Queens in the following neighborhoods: Flushing-Clearview, Bayside-Little Neck, and Southeast Queens; and unsurprisingly in Manhattan in Union Square-Lower East Side.

Taken together, in comparison to Figures 1 and 2, Figures 7 and 8 show that greater rates of mortality from COVID-19 are found in ZCTAs that have larger shares of Asian population, as compared to White population, regardless of nativity status. Also notable is the fact that the location of neighborhoods with large percentages of native- and foreign-born Asians (in Figures 7 and 8, respectively), regardless of COVID-19 mortality rates, is different from those containing larger shares of native- and foreign-born White populations (in Figures 1 and 2, respectively). The differing distributions of the geographic locations of White and Asian components of the population is consistent with the fact that the NYC's level of White-Asian residential segregation is the seventh highest out of America's largest 200 cities (Logan and Stults 2011).

\section{Discussion and Conclusions}

The main objective of this study was to examine the relation between spatial variation in COVID-19 mortality rates and the racial, ethnic, and nativity status composition of populations across neighborhoods in NYC. We sought to identify communities of color and immigrants in NYC that have been hardest hit by the pandemic using a novel, bivariate mapping approach. This allowed us to overcome the data limitation of not having available neighborhood-level mortality 
rates disaggregated by race, ethnicity, and nativity status. In addition, we attempted to offer insights as to why some of these communities were more vulnerable to COVD-19 mortality than others.

Our descriptive, bivariate maps reveals that a hierarchy emerges on the basis of racial, ethnic, and to a lesser extent, nativity status composition, in the communities hardest hit by COVID-19 mortality. Communities with large shares of native-born, White population have fared best in terms of experiencing the lowest levels of COVID-19 mortality, and communities with large shares of native- and foreign-born Black populations have fared the worst. There are slightly more neighborhoods with large shares of foreign-born whites, relative to those with large shares of native-born Whites, that have the highest levels of COVID-19 mortality. Neighborhoods composed of large percentages of native- and foreign-born Hispanic populations fare somewhat better than neighborhoods with disproportionate shares of blacks, but the difference is not that profound. On the other hand, neighborhoods with high shares of native- and foreign-born Asians fall in the middle of the hierarchy of places on the continuum of COVID-19 mortality rates. There are many neighborhoods with large shares of native- and foreign-born Asian populations that have the lowest levels of COVID-19 deaths, per 100,000 population, but the number of neighborhoods is still not as high as it is for the native-born White population. What is clear from our analysis is that the residential segregation of Blacks, Hispanics, and Asians from Whites makes neighborhoods with non-White shares of the population more vulnerable to COVID-19 mortality. But the underlying reasons for the vulnerability to COVID19 likely differs by the racial, ethnic, and nativity-status component of the population. Consistent with the tenets of the place stratification model, decades of structural racism make Black communities more vulnerable to experiencing concentrated disadvantage, poorer health, 
and increased levels of mortality, particularly from COVID-19 (Krieger et al. 2020; Nardone et al. 2020; Phelan and Link 2015; Williams and Collins 2001). This likely explains why few neighborhoods with large shares of native- and foreign-born Blacks experience the lowest levels of COVID-19 mortality. Hispanics, and particularly Dominicans, have also experience structural racism, and this also likely explains their residence in neighborhoods with high levels of COVID-19 mortality (Rosenbaum and Friedman 2007).

However, the tenets of the place stratification model cannot fully explain variation in COVID-19 mortality across NYC neighborhoods. The analyses here show that the residential distribution of many Hispanics and most Asians do not overlap with Blacks in NYC, which is consistent with previous research (Logan and Stults 2011). In 2010, the Hispanic-Black level of segregation in New York City in 2010 was 55, and the Black-Asian D-score was 78 (Logan and Stults 2011). Recent research has shown that most of the racially integrated neighborhoods in New York City do not contain Blacks (Lobo et al. 2019).

Our analyses, however, shows that communities with large shares of Hispanics and Asians are also vulnerable to COVID-19 mortality. Consistent with the tenets of the spatial assimilation, it is likely that such high levels of mortality have resulted from the extensive social networks that Hispanics and Asians have, living in largely immigrant neighborhoods. Moreover, because many of the deaths in NYC resulted from the population becoming ill at the outset of the pandemic, when masks were not mandated and stay-at-home orders were not in place, we suspect that communities of immigrants may have been more vulnerable because of contact with co-ethnics and particularly those who recently traveled from overseas.

The analysis presented here makes clear that the pandemic has significantly exacerbated spatial inequalities in NYC that already existed well before COVID-19 and particularly between 
Blacks and Whites. Decades of racial and ethnic residential segregation and disinvestment and the resultant poverty and unemployment have tragically ended the lives of so many in NYC and particularly among Blacks. To put this racial inequality in perspective, Wrigley-Field (2020:21854) finds that "for White life expectancy in 2020 to fall to the level of the bestrecorded Black life expectancy would require an estimated 700,000 to 1 million excess White deaths." The results in this study should serve as a wake-up call to policymakers to invest more resources in Black communities in NYC, particularly in terms of education, housing, and health care, so that future Black lives are not lost. 


\section{References}

Alba, R.D. and J.R. Logan. 1991. "Variation on Two Themes: Racial and Ethnic Patterns in Attainment of Suburban Residence." Demography 28:431-53.

Bajgain, K.T., S. Badal, B.B. Bajgain, and M.J. Santana. 2021. "Prevalence of Comorbidities among Individuals with COVID-19: A Rapid Review of the Current Literature." American Journal of Infection Control 49(2):238-246.

Charles, C.Z. 2003. "The Dynamics of Racial Residential Segregation.” Annual Review of Sociology 29:167-207.

Crowder, K. and L. Tedrow. 2001. "West Indians and the Residential Landscape in New York." In Islands in the City: West Indian Migration to New York, edited by Nancy Foner. Berkeley: University of California Press.

Cunningham, S.A., J.D. Ruben, and K.M. Venkat Narayan. 2008. "Health of Foreign-Born People in the United States: A Review." Health \& Place 14(4):623-635.

DiMaggio, C., M. Klein, C. Berry, and S. Frangos. 2020. "Black/African American Communities are at Highest Risk of COVID-19: Spatial Modeling of New York City Zip Code-Level Testing Results.” Annals of Epidemiology 51:7-13.

Foner, N. 2000. From Ellis Island to JFK: New York's Two Great Waves of Immigration. New Haven, CT: Yale University Press.

Hooper, M.W., A.M. Napoles, and E.J. Perez Stable. 2020. "COVID-19 and Racial/Ethnic Disparities.” JAMA 323(24):2466-2467. doi:10.1001/jama.2020.8598

Hotchkiss, M. 2015. "Hypersegregated Cities Face Tough Road to Change.” Retrieved December 5, 2020. https://www.princeton.edu/news/2015/05/18/hypersegregated-citiesface-tough-road-change

Iceland, J. and K.A. Nelson. 2008. "Hispanic Segregation in Metropolitan America: Exploring the Multiple Forms of Spatial Assimilation." American Sociological Review 73:741-765.

Iceland, J., and M. Scopilliti. 2008. "Immigrant Residential Segregation in US Metropolitan Areas, 1990-2000." Demography 45(1): 79-94.

Iceland, J. and R. Wilkes. 2006. "Does Socioeconomic Status Matter? Race, Class, and Residential Segregation." Social Problems 53(2):248-273.

Intrator, J., J. Tannen, and D.S. Massey. 2016. "Segregation by Race and Income in the United States, 1970-2010.” Social Science Research 60:45-60.

Jackson, K. 1985. Crabgrass Frontier: The Suburbanization of the United States. New York: Oxford University Press. 
Kasinitz, P. 1992. Caribbean New York: Black Immigrants and the Politics of Race. Ithaca, NY: Cornell University Press.

Krieger, N., G. Van Wye, M. Huynh, P.D. Waterman, G. Maduro, W. Li, R.C. Gwynn, O. Barbot, and M.T. Bassett. 2020. "Structural Racism, Historical Redlining, and Risk of Preterm Birth in New York City, 2013-2017.” American Journal of Public Health 110(7):1046-1053.

Kucheva, Y. and R. Sander. 2018. "Structural Versus Ethnic Dimensions of Housing Segregation.” Journal of Urban Affairs 40(3):329-348.

Lieberman-Cribbin, W., S. Tuminello, R.M. Flores, and E. Taioli. 2020. "Disparities in COVID19 Testing and Positivity in New York City." American Journal of Preventive Medicine 59(3):326-332.

Lobo, A.P., R.J.O. Flores, and J.J. Salvo. 2019. "Racial Differentials in the Components of Population Change and Neighborhood Transitions in New York City, 1980-2010: The Distinct Role of Asian Net Inflows in the Age of Net Outflows of Whites, Blacks, and Hispanics." Urban Affairs Review 55(5):1456-1486.

Lobo, A.P. and J.J. Salvo. 2013. The Newest New Yorkers: Characteristics of the City's Foreignborn Population, 2013 Edition. New York: New York City Department of City Planning.

Logan, J.R., R.D. Alba, and W. Zhang. 2002. "Immigrant Enclaves and Ethnic Communities in New York and Los Angeles.” American Sociological Review 67(2):299-322.

Logan, J.R. and H. Molotch. 1987. Urban Fortunes. Berkeley, CA: University of California Press.

Logan, J.R. and B. Stults. 2011. "Diversity and Disparities: Residential Segregation by Race/Ethnicity - Sortable Lists of Segregation by Race/Ethnicity for the 200 Largest Cities." Retrieved February 16, 2021. https://s4.ad.brown.edu/Projects/Diversity/SegCitySorting/Default.aspx

Massey, D.S. 1985. "Ethnic Residential Segregation: A Theoretical Synthesis and Empirical Review." Sociology and Social Research 69(3): 315-50.

Massey, D.S. and N.A. Denton. 1993. American Apartheid: Segregation and the Making of the Underclass. Cambridge, MA: Harvard University Press.

Massey, D.S. and J.Tannen. 2015. "A Research Note on Trends in Black Hypersegregation.” Demography 52:1025-1034.

Millett, G.A., A.T. Jones, D. Benkeser, S. Baral, L. Mercer, C. Beyrer, B. Honermann, E. Lankiewicz, L. Mena, J.S. Crowley, J. Sherwood, and P.S. Sullivan. 2020. “Assessing 
Differential Impacts of COVID-19 on Black Communities.” Annals of Epidemiology 47:37-44.

Nardone, A., J. Chiang, and J. Corburn. 2020. "Historic Redlining and Urban Health Today in U.S. Cities.” Environmental Justice 13(4):109-119.

NYC DOH (New York City Department of Health). 2021a. COVID-19: Data - Main Data Page. Retrieved February 1, 2021. (https://www1.nyc.gov/site/doh/covid/covid-19-data.page).

NYC DOH. 2021b. All About Geography: The Neighborhood Boundaries on the EH Data Portal. UHF Codes. Retrieved March 1, 2021 (http://a816dohbesp.nyc.gov/IndicatorPublic/Closerlook/geographies/index.html and https://www1.nyc.gov/assets/doh/downloads/pdf/ah/zipcodetable.pdf)

NYU Furman Center. 2018. State of New York City's Housing and Neighborhoods in 2018. New York: New York University.

Phelan, J.C. and B.G. Link. 2015. "Is Racism a Fundamental Cause of Inequalities in Health?" Annual Review of Sociology 41:311-330.

Rosenbaum, E. and S. Friedman. 2007. The Housing Divide: How Generations of Immigrants Fare in New York's Housing Market. New York, NY: New York University Press.

Ssentongo, P., A.E. Ssentongo, E.S. Heilbrunn, D.M. Ba, and V.M. Chinchilli. 2020. "Association of Cardiovascular Disease and 10 Other Pre-Existing Comorbidities with COVID-19 Mortality: A Systematic Review and Meta-Analysis." Plos One 15(8):e0238215. https://doi.org/10.1371/journal.pone.0238215

Strully, K., T.C. Yang, and H. Liu. 2020. "Regional Variation in COVID-19 Disparities: Connections with Immigrant and Latinx Communities in US Counties." Annals of Epidemiology. https://doi.org/10.1016/j.annepidem.2020.08.016

Torrats-Espinosa, G. 2021. "Using Machine Learning to Estimate the Effect of Racial Segregation on COVID-19 Mortality in the United States." PNAS 118(7):32015577118.

Turner, M.A., R. Santos, D.K. Levy, D. Wissoker, C. Aranda, and R. Pitingolo. 2013. Housing Discrimination against Racial and Ethnic Minorities, 2012. Washington, DC: Urban Institute.

U.S. Census Bureau. 2020a. Table B05002. Place of Birth by Nativity Status and Citizenship Status. 2019: American Community Survey 5-Year Estimates Detailed Tables - US and NYC. Retrieved February 26, 2021. https://data.census.gov.

U.S. Census Bureau. 2020b. Tables B06004B, B06004D, B06004H, B06004I. Place of Birth in the United States. 2019: American Community Survey 5-Year Estimates Detailed Tables - US and NYC - for (Black or African American Alone; Asian Alone; White Alone, Not 
Hispanic or Latino); and Hispanic or Latino, respectively. Retrieved February 26, 2021. https://data.census.gov.

U.S. Census Bureau. 2020c. Table B03002. Hispanic or Latino Origin by Race. 2019: American Community Survey 1-Year Estimates Detailed Tables. Retrieved January 16, 2021. https://data.census.gov.

U.S. Centers for Disease Control and Prevention. 2020. COVID-19 in Racial and Ethnic Minority Groups. Centers for Disease Control and Prevention.

USA Facts. 2020. US Coronavirus Cases and Deaths. Retrieved December 14, 2020. https://usafacts.org/visualizations/coronavirus-covid-19-spread-map/

Wadhera, R.K., P. Wadhera, P. Gaba, J.F. Figueroa, K.E. Joynt Maddox, R.W. Yeh, and C. Shen. 2020. "Variation in COVID-19 Hospitalizations and Deaths across New York City Boroughs." JAMA 323(21):2192-2195.

Wilder, C.S. 2000. A Covenant with Color. New York: Columbia University Press.

Williams, D.R. and C. Collins. 2001. "Racial Residential Segregation: A Fundamental Cause of Racial Disparities in Health.” Public Health Reports 116:404-416.

Wrigley-Field, E. 2020. "US Racial Inequality May Be as Deadly as COVID-19.” PNAS 117(36):21854-21856.

Yancy, C. 2020. "COVID-19 and African Americans." Viewpoint Journal of the American Medical Association April 15. 
Figure 1. COVID-19 Mortality Rate and Percent Native-born, Non-Hispanic Whites by ZCTAs, New York City

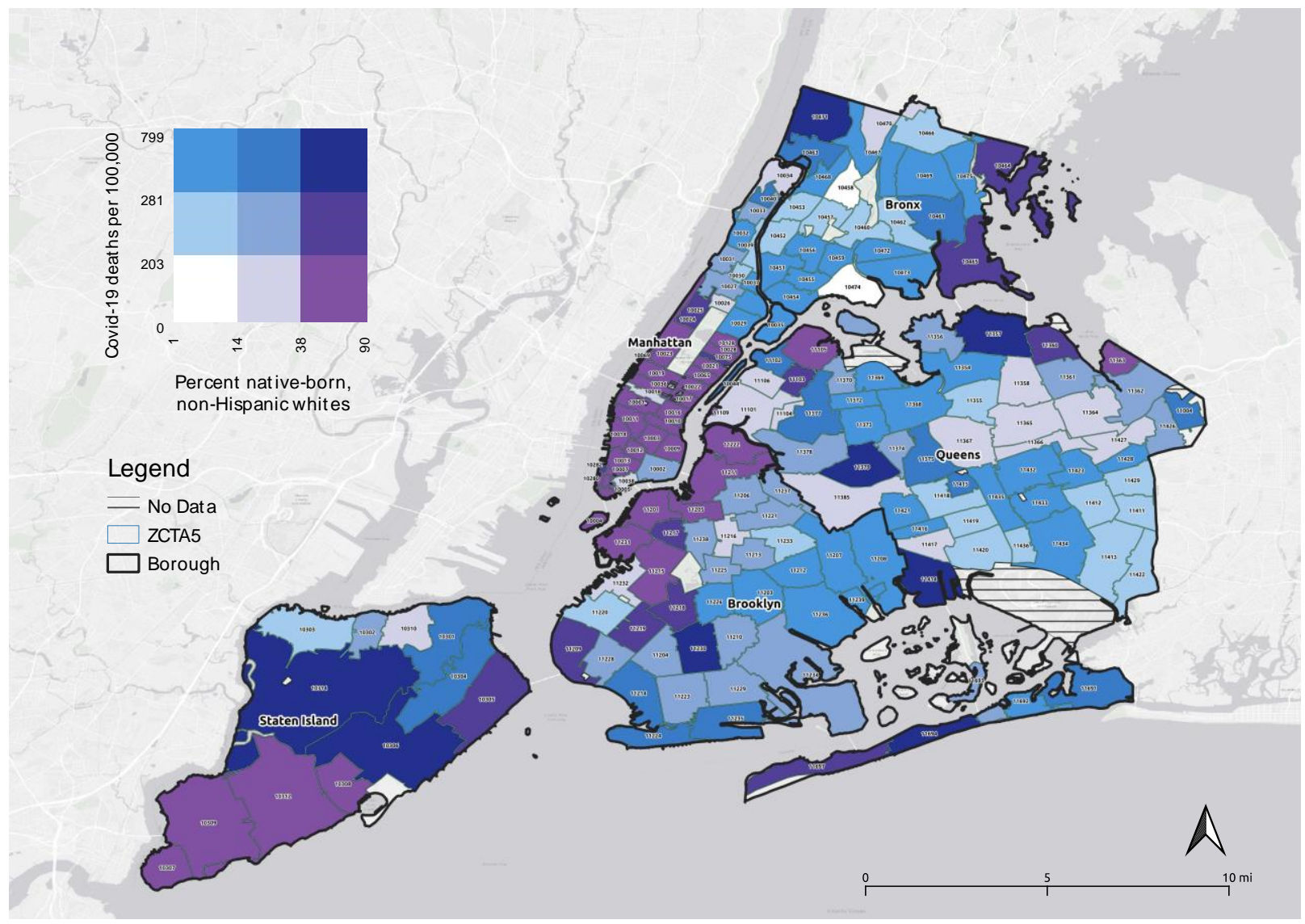


Figure 2. COVID-19 Mortality Rate and Percent Foreign-born, Non-Hispanic Whites by ZCTAs, New York City

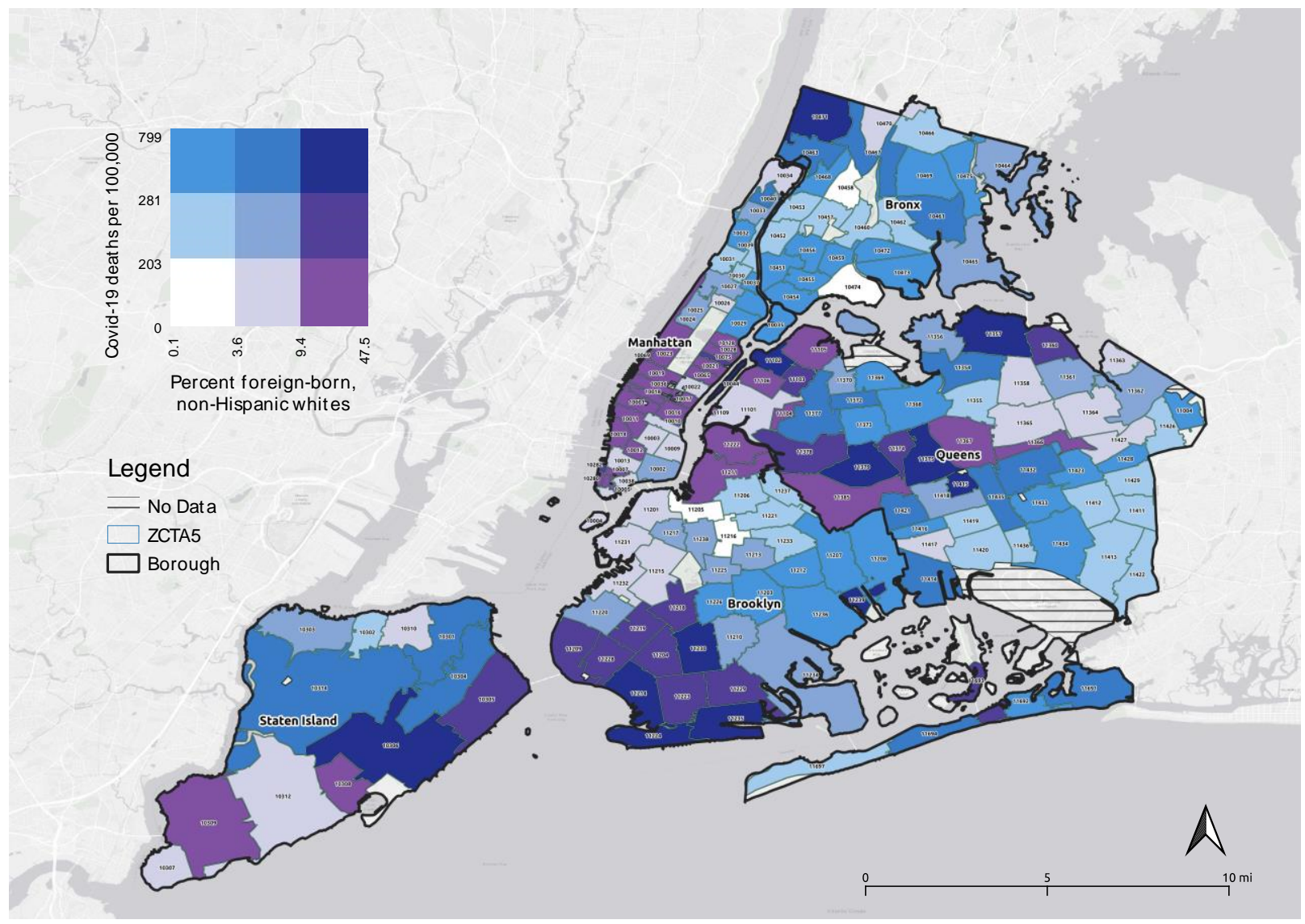


Figure 3. COVID-19 Mortality Rate and Percent Native-born Blacks by ZCTAs, New York City

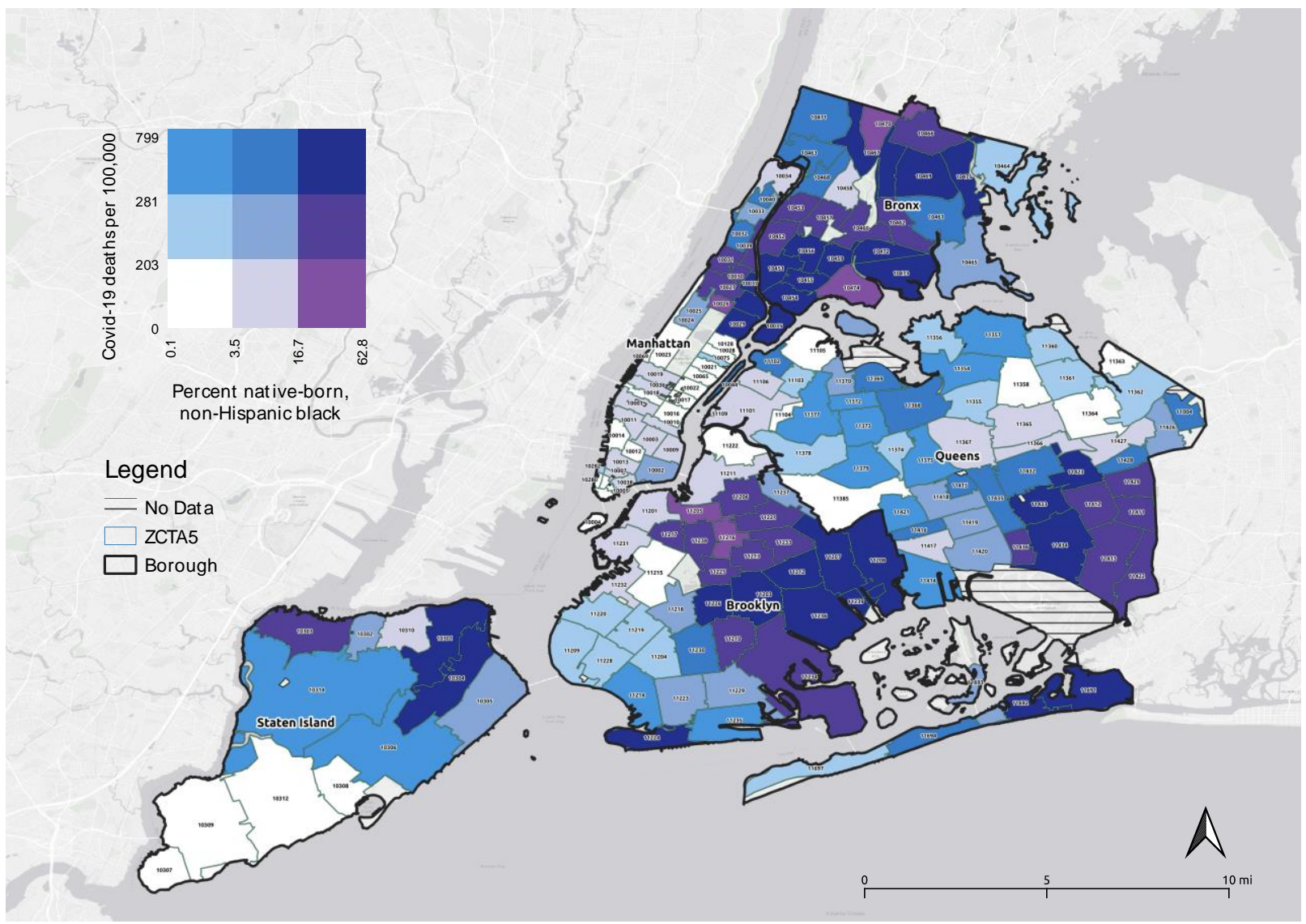


Figure 4. COVID-19 Mortality Rate and Percent Foreign-born Blacks by ZCTAs, New York City

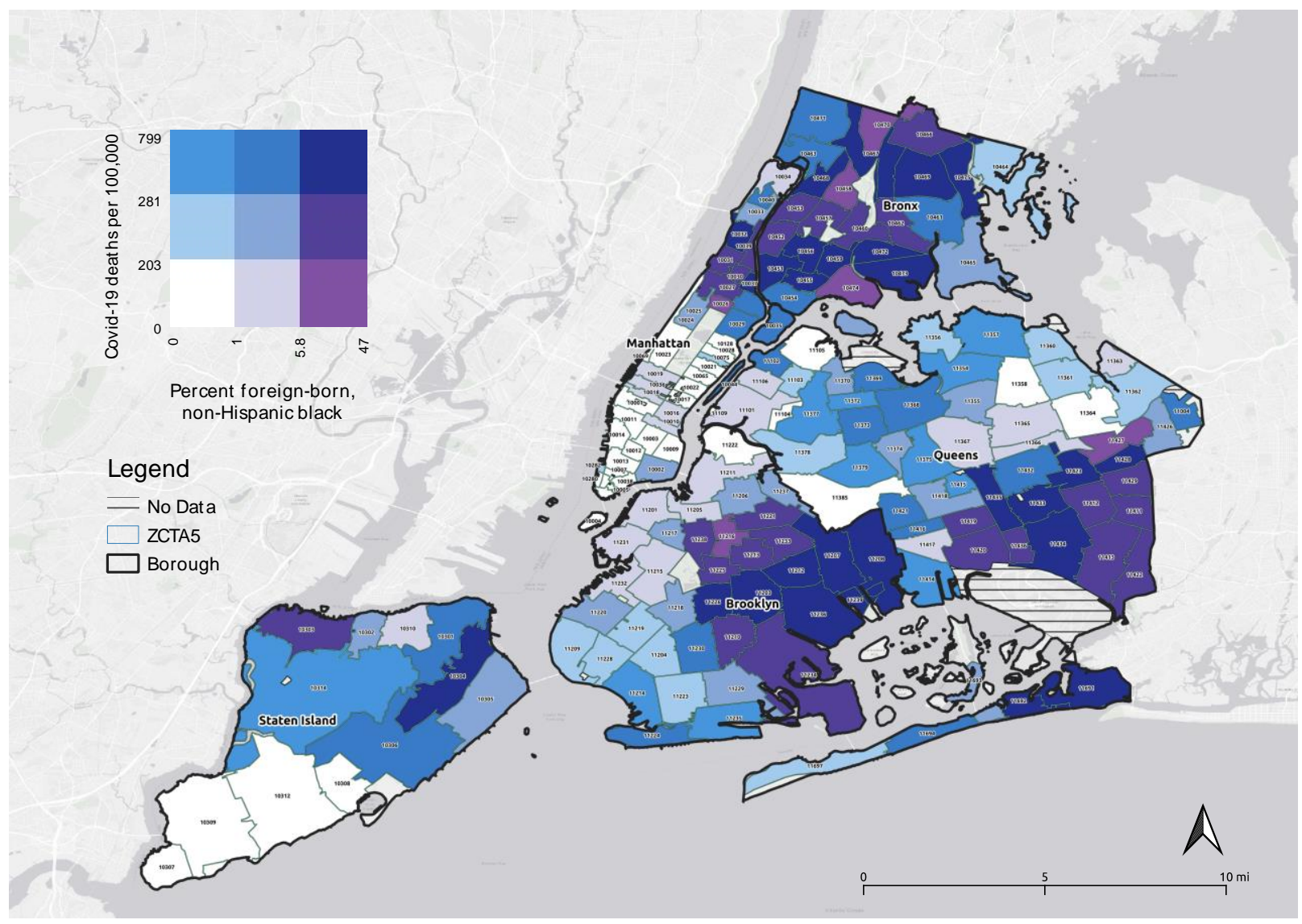


Figure 5. COVID-19 Mortality Rate and Percent Native-born Hispanics by ZCTAs, New York City

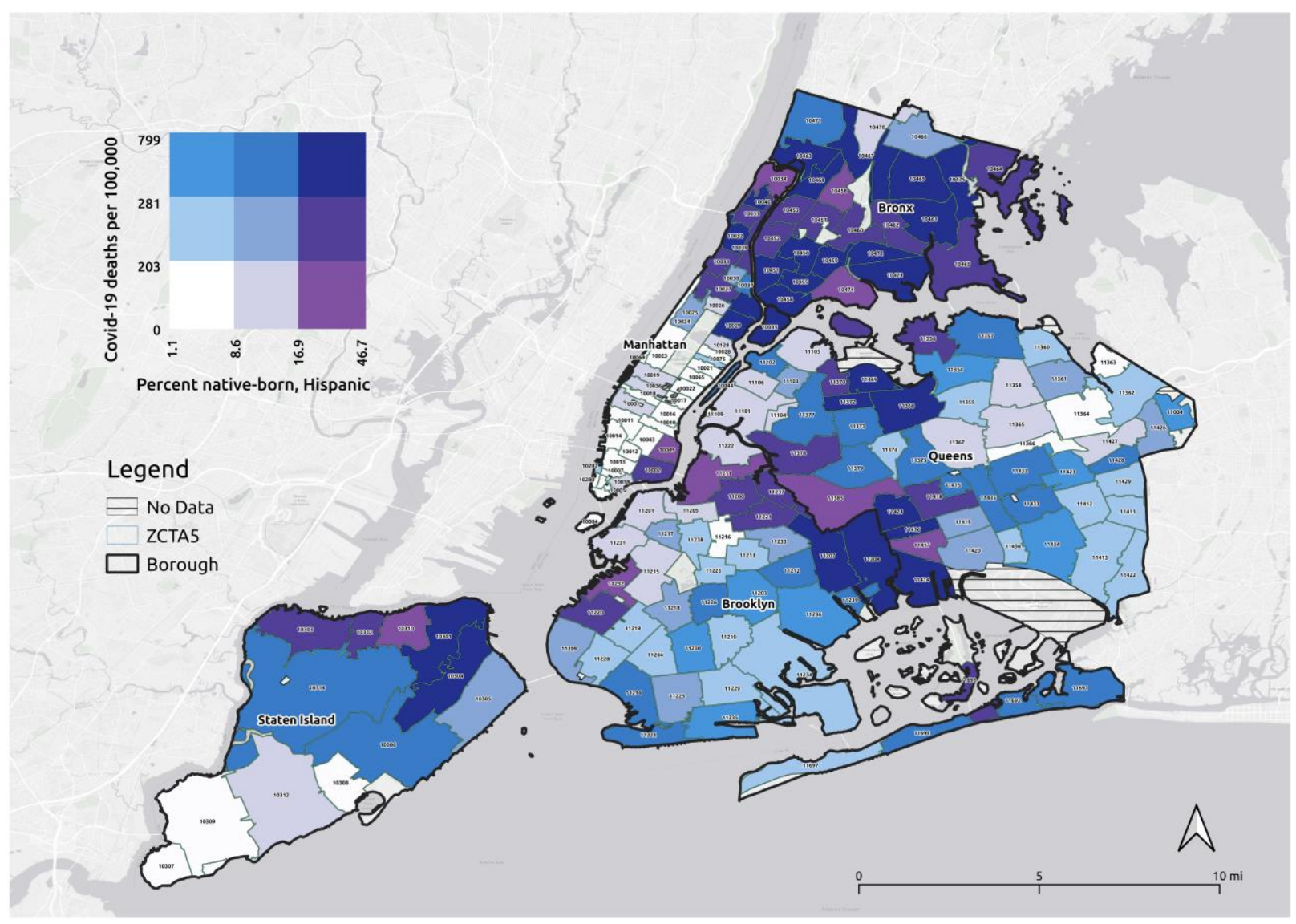


Figure 6. COVID-19 Mortality Rate and Percent Foreign-born Hispanics by ZCTAs, New York City

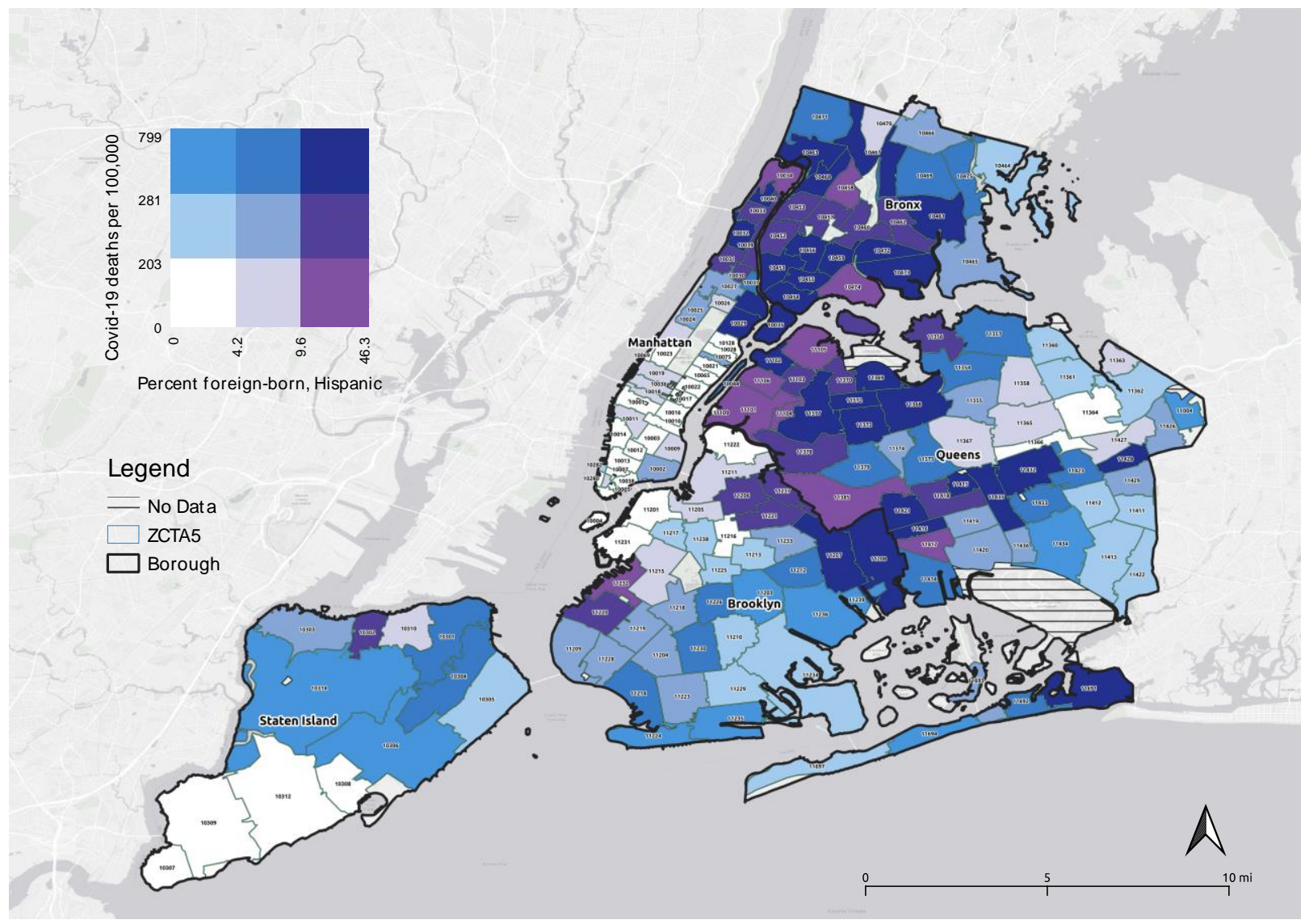


Figure 7. COVID-19 Mortality Rate and Percent Native-born Asians by ZCTAs, New York City

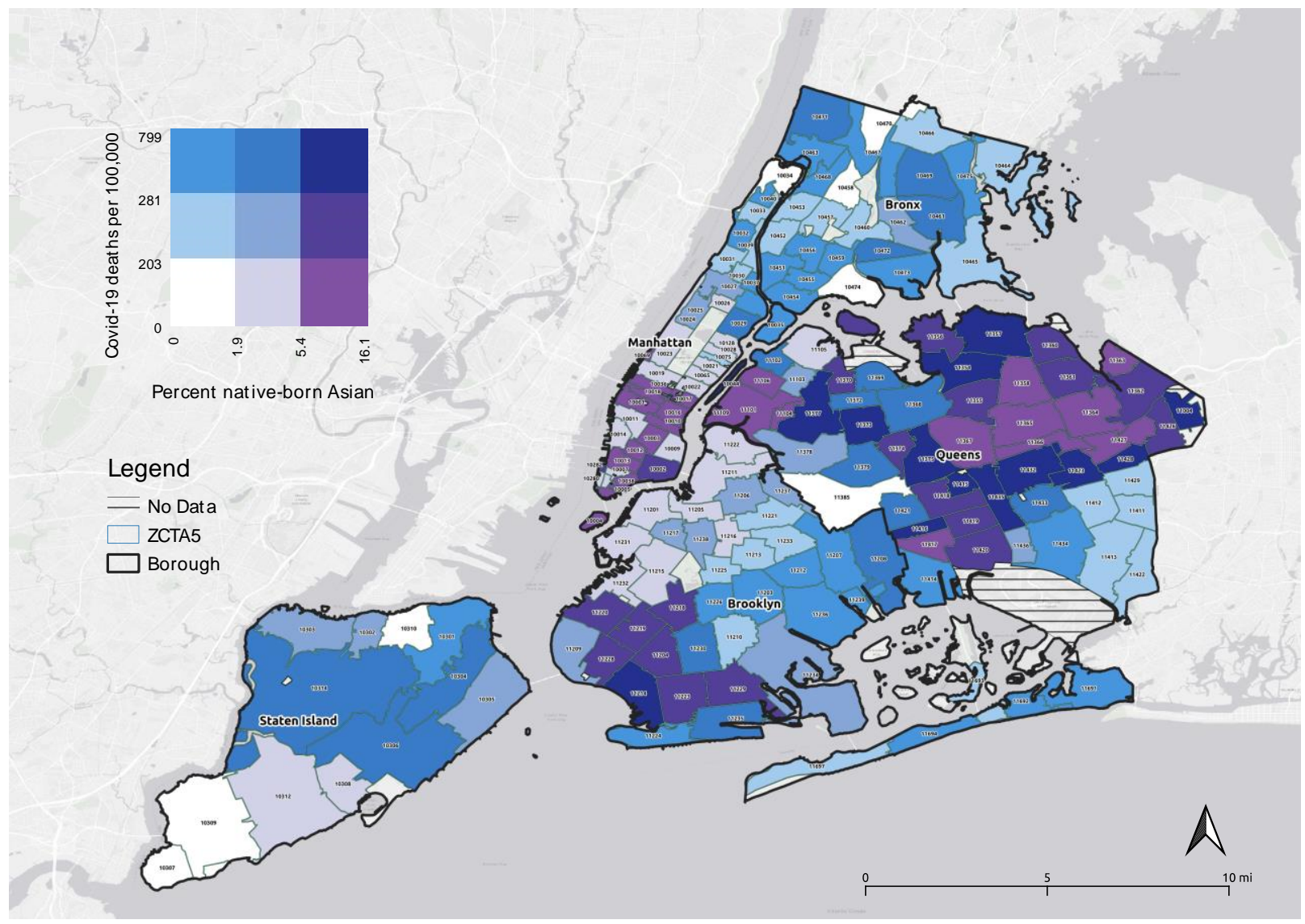


Figure 8. COVID-19 Mortality Rate and Percent Foreign-born Asians by ZCTAs, New York City

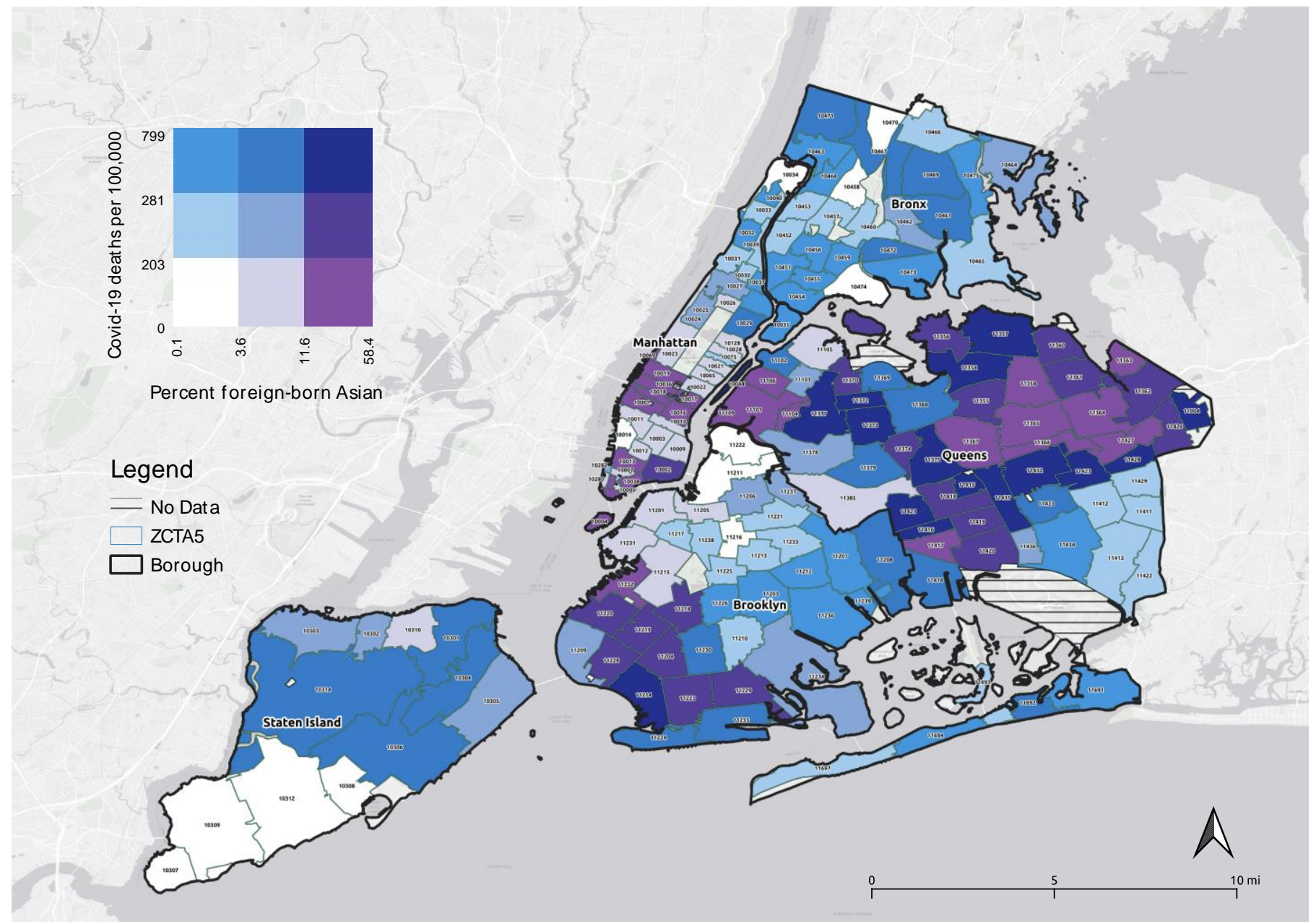


Appendix Map 1. Reference Map of ZCTAs in New York City

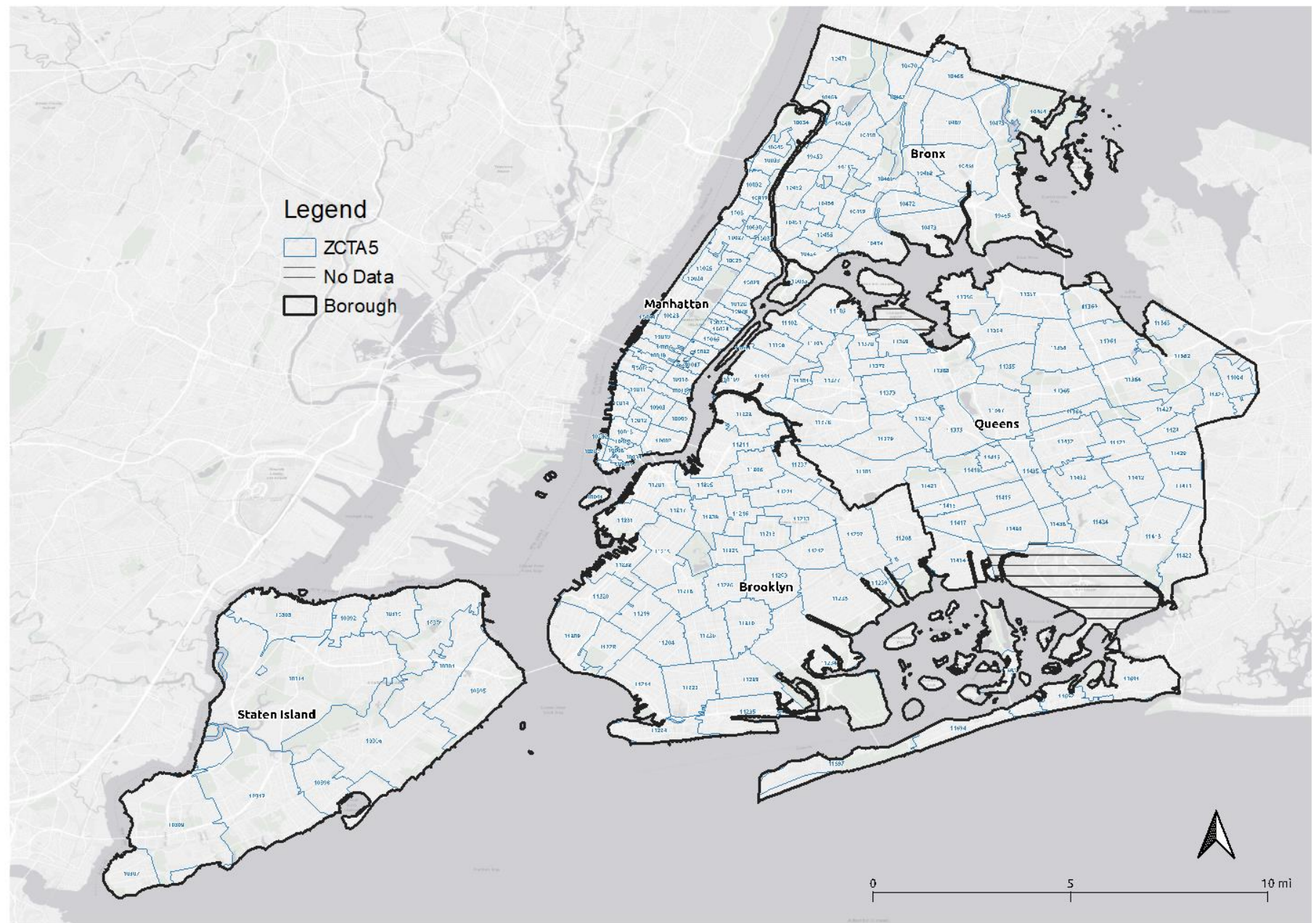




\section{Appendix Table 1. ZCTAs in New York City by Borough and Neighborhood Names}

\begin{tabular}{|c|c|c|c|c|c|}
\hline ZCTA & Borough & Neighborhood Name & ZCTA & Borough & Neighborhood Name \\
\hline 10001 & Manhattan & Chelsea-Clinton & 11204 & Brooklyn & Borough Park \\
\hline 10002 & Manhattan & Union Square-Lower East Side & 11205 & Brooklyn & Downtown-Heights-Park Slope \\
\hline 10003 & Manhattan & Union Square-Lower East Side & 11206 & Brooklyn & Williamsburg-Bushwick \\
\hline 10004 & Manhattan & Lower Manhattan & 11207 & Brooklyn & East New York \\
\hline 10005 & Manhattan & Lower Manhattan & 11208 & Brooklyn & East New York \\
\hline 10006 & Manhattan & Lower Manhattan & 11209 & Brooklyn & Bensonhurst-Bay Ridge \\
\hline 10007 & Manhattan & Lower Manhattan & 11210 & Brooklyn & East Flatbush-Flatbush \\
\hline 10009 & Manhattan & Union Square-Lower East Side & 11211 & Brooklyn & Greenpoint \\
\hline 10010 & Manhattan & Gramercy Park-Murray Hill & 11212 & Brooklyn & Bedford Stuyvesant-Crown Heights \\
\hline 10011 & Manhattan & Chelsea-Clinton & 11213 & Brooklyn & Bedford Stuyvesant-Crown Heights \\
\hline 10012 & Manhattan & Greenwich Village-SoHo & 11214 & Brooklyn & Bensonhurst-Bay Ridge \\
\hline 10013 & Manhattan & Greenwich Village-SoHo & 11215 & Brooklyn & Downtown-Heights-Park Slope \\
\hline 10014 & Manhattan & Greenwich Village-SoHo & 11216 & Brooklyn & Bedford Stuyvesant-Crown Heights \\
\hline 10016 & Manhattan & Gramercy Park-Murray Hill & 11217 & Brooklyn & Downtown-Heights-Park Slope \\
\hline 10017 & Manhattan & Gramercy Park-Murray Hill & 11218 & Brooklyn & Borough Park \\
\hline 10018 & Manhattan & Chelsea-Clinton & 11219 & Brooklyn & Borough Park \\
\hline 10019 & Manhattan & Chelsea-Clinton & 11220 & Brooklyn & Sunset Park \\
\hline 10020 & Manhattan & Chelsea-Clinton & 11221 & Brooklyn & Williamsburg-Bushwick \\
\hline 10021 & Manhattan & Upper East Side & 11222 & Brooklyn & Greenpoint \\
\hline 10022 & Manhattan & Gramercy Park-Murray Hill & 11223 & Brooklyn & Coney Island-Sheepshead Bay \\
\hline 10023 & Manhattan & Upper West Side & 11224 & Brooklyn & Coney Island-Sheepshead Bay \\
\hline 10024 & Manhattan & Upper West Side & 11225 & Brooklyn & East Flatbush-Flatbush \\
\hline 10025 & Manhattan & Upper West Side & 11226 & Brooklyn & East Flatbush-Flatbush \\
\hline 10026 & Manhattan & Central Harlem-Morningside Heights & 11228 & Brooklyn & Bensonhurst-Bay Ridge \\
\hline 10027 & Manhattan & Central Harlem-Morningside Heights & 11229 & Brooklyn & Coney Island-Sheepshead Bay \\
\hline 10028 & Manhattan & Upper East Side & 11230 & Brooklyn & Borough Park \\
\hline 10029 & Manhattan & East Harlem & 11231 & Brooklyn & Downtown-Heights-Park Slope \\
\hline 10030 & Manhattan & Central Harlem-Morningside Heights & 11232 & Brooklyn & Sunset Park \\
\hline 10031 & Manhattan & Washington Heights-Inwood & 11233 & Brooklyn & Bedford Stuyvesant-Crown Heights \\
\hline 10032 & Manhattan & Washington Heights-Inwood & 11234 & Brooklyn & Canarsie-Flatlands \\
\hline 10033 & Manhattan & Washington Heights-Inwood & 11235 & Brooklyn & Coney Island-Sheepshead Bay \\
\hline 10034 & Manhattan & Washington Heights-Inwood & 11236 & Brooklyn & Canarsie-Flatlands \\
\hline 10035 & Manhattan & East Harlem & 11237 & Brooklyn & Williamsburg-Bushwick \\
\hline 10036 & Manhattan & Chelsea-Clinton & 11238 & Brooklyn & Bedford Stuyvesant-Crown Heights \\
\hline 10037 & Manhattan & Central Harlem-Morningside Heights & 11239 & Brooklyn & Canarsie-Flatlands \\
\hline 10038 & Manhattan & Lower Manhattan & 11354 & Queens & Flushing-Clearview \\
\hline 10039 & Manhattan & Central Harlem-Morningside Heights & 11355 & Queens & Flushing-Clearview \\
\hline 10040 & Manhattan & Washington Heights-Inwood & 11356 & Queens & Flushing-Clearview \\
\hline 10044 & Manhattan & Upper East Side & 11357 & Queens & Flushing-Clearview \\
\hline 10128 & Manhattan & Upper East Side & 11358 & Queens & Flushing-Clearview \\
\hline 10280 & Manhattan & Lower Manhattan & 11359 & Queens & Flushing-Clearview \\
\hline 10301 & Staten Island & Stapleton-St. George & 11360 & Queens & Flushing-Clearview \\
\hline 10302 & Staten Island & Port Richmond & 11361 & Queens & Bayside-Little Neck \\
\hline 10303 & Staten Island & Port Richmond & 11362 & Queens & Bayside-Little Neck \\
\hline 10304 & Staten Island & Stapleton-St. George & 11363 & Queens & Bayside-Little Neck \\
\hline 10305 & Staten Island & Stapleton-St. George & 11364 & Queens & Bayside-Little Neck \\
\hline 10306 & Staten Island & South Beach-Tottenville & 11365 & Queens & Fresh Meadows \\
\hline
\end{tabular}




\begin{tabular}{|c|c|c|c|c|c|}
\hline \multicolumn{6}{|c|}{ Appendix Table 1 (cont'd). ZCTAs in New York City by Borough and Neighborhood Names } \\
\hline 10307 & Staten Island & South Beach-Tottenville & 11366 & Queens & Fresh Meadows \\
\hline 10308 & Staten Island & South Beach-Tottenville & 11367 & Queens & Fresh Meadows \\
\hline 10309 & Staten Island & South Beach-Tottenville & 11368 & Queens & West Queens \\
\hline 10310 & Staten Island & Port Richmond & 11369 & Queens & West Queens \\
\hline 10312 & Staten Island & South Beach-Tottenville & 11370 & Queens & West Queens \\
\hline 10314 & Staten Island & Willowbrook & 11372 & Queens & West Queens \\
\hline 10451 & Bronx & High Bridge-Morrisania & 11373 & Queens & West Queens \\
\hline 10452 & Bronx & High Bridge-Morrisania & 11374 & Queens & Ridgewood-Forest Hills \\
\hline 10453 & Bronx & Crotona-Tremont & 11375 & Queens & Ridgewood-Forest Hills \\
\hline 10454 & Bronx & Hunts Point-Mott Haven & 11377 & Queens & West Queens \\
\hline 10455 & Bronx & Hunts Point-Mott Haven & 11378 & Queens & West Queens \\
\hline 10456 & Bronx & High Bridge-Morrisania & 11379 & Queens & Ridgewood-Forest Hills \\
\hline 10457 & Bronx & Crotona-Tremont & 11385 & Queens & Ridgewood-Forest Hills \\
\hline 10458 & Bronx & Fordham-Bronx Park & 11411 & Queens & Southeast Queens \\
\hline 10459 & Bronx & Hunts Point-Mott Haven & 11412 & Queens & Jamaica \\
\hline 10460 & Bronx & Crotona-Tremont & 11413 & Queens & Southeast Queens \\
\hline 10461 & Bronx & Pelham-Throgs Neck & 11414 & Queens & Southwest Queens \\
\hline 10462 & Bronx & Pelham-Throgs Neck & 11415 & Queens & Southwest Queens \\
\hline 10463 & Bronx & Kingsbridge-Riverdale & 11416 & Queens & Southwest Queens \\
\hline 10464 & Bronx & Pelham-Throgs Neck & 11417 & Queens & Southwest Queens \\
\hline 10465 & Bronx & Pelham-Throgs Neck & 11418 & Queens & Southwest Queens \\
\hline 10466 & Bronx & Northeast Bronx & 11419 & Queens & Southwest Queens \\
\hline 10467 & Bronx & Fordham-Bronx Park & 11420 & Queens & Southwest Queens \\
\hline 10468 & Bronx & Fordham-Bronx Park & 11421 & Queens & Southwest Queens \\
\hline 10469 & Bronx & Northeast Bronx & 11422 & Queens & Southeast Queens \\
\hline 10470 & Bronx & Northeast Bronx & 11423 & Queens & Jamaica \\
\hline 10471 & Bronx & Kingsbridge-Riverdale & 11426 & Queens & Southeast Queens \\
\hline 10472 & Bronx & Pelham-Throgs Neck & 11427 & Queens & Southeast Queens \\
\hline 10473 & Bronx & Pelham-Throgs Neck & 11428 & Queens & Southeast Queens \\
\hline 10474 & Bronx & Hunts Point-Mott Haven & 11429 & Queens & Southeast Queens \\
\hline 10475 & Bronx & Northeast Bronx & 11432 & Queens & Jamaica \\
\hline 11004 & Queens & Southeast Queens & 11433 & Queens & Jamaica \\
\hline 11005 & Queens & Southeast Queens & 11434 & Queens & Jamaica \\
\hline 11101 & Queens & Long Island City-Astoria & 11435 & Queens & Jamaica \\
\hline 11102 & Queens & Long Island City-Astoria & 11436 & Queens & Jamaica \\
\hline 11103 & Queens & Long Island City-Astoria & 11691 & Queens & Rockaway \\
\hline 11104 & Queens & Long Island City-Astoria & 11692 & Queens & Rockaway \\
\hline 11105 & Queens & Long Island City-Astoria & 11693 & Queens & Rockaway \\
\hline 11106 & Queens & Long Island City-Astoria & 11694 & Queens & Rockaway \\
\hline 11201 & Brooklyn & Downtown-Heights-Park Slope & 11695 & Queens & Rockaway \\
\hline 11203 & Brooklyn & East Flatbush-Flatbush & 11697 & Queens & Rockaway \\
\hline
\end{tabular}

